\title{
Absorption and metabolism of yerba mate phenolic compounds in humans
}

Authors: Miren Gómez-Juaristi, Sara Martínez-López, Beatriz Sarria, Laura Bravo* and Raquel Mateos*

Address: Department of Metabolism and Nutrition, Institute of Food Science, Technology and Nutrition (ICTAN-CSIC). Spanish National Research Council (CSIC), José Antonio Nováis 10, 28040 Madrid.

*Corresponding authors:

Raquel Mateos Briz (raquel.mateos@ictan.csic.es)

Laura Bravo-Clemente (Ibravo@ictan.csic.es)

Department of Metabolism and Nutrition

Institute of Food Science, Technology and Nutrition (ICTAN-CSIC). Spanish National Research Council (CSIC)

C/ José Antonio Nováis 10, 28040 Madrid, Spain.

Tel. +34.915492300 


\section{ABSTRACT}

Bioavailability of yerba mate phenolic compounds was assessed in healthy humans. Up 34 metabolites were identified in biological fluids, mainly sulfated conjugates of caffeic and ferulic/isoferulic acids, in addition to non-metabolized caffeoyl-, feruloyl-, and $p$ coumaroilquinic acids, with rapid appearance and clearance in plasma indicative of small intestinal absorption. These compounds amounted $13.1 \%$ of the urinary metabolites. Delayed absorption of dihydrocaffeic, dihydroferulic and dihydrocoumaric acids and their phase II metabolites, in addition to feruloylglycine, pointed to their microbial origin and colonic absorption, accounting for $81.0 \%$ of excreted metabolites. Phase II flavonol metabolites $(0.2 \%)$ derived mainly from rutin after colonic transformation and absorption were also detected. Additionally, dihydroferuloyl-, dihydrocaffeoyl- and dihydrocoumaroylquinic acids (5.7\%) were identified, showing the most delayed kinetics. Total phenolic excretion (147.6 $\mu \mathrm{mol})$ corresponded to $13.2 \%$ of ingested phenols. In conclusion, mate polyphenols are partially bioavailable and extensively metabolized, mainly by the microbiota.

KEYWORDS: hydroxycinnamate derivatives, flavonols, yerba mate, bioavailability, LC-MS-QToF, colonic microbiota. 


\section{INTRODUCTION}

Mate or yerba mate is a tea-like beverage prepared from the leaves of Ilex paraguariensis (Saint Hilaire, Aquifoliaceae), a species native of subtropical regions in South America. This beverage is very popular in countries like Brazil, Paraguay, Uruguay and Argentina, with daily intakes over $1 \mathrm{~L} /$ person. Its consumption is growing worldwide due to migratory movements and cultural exchanges and, more recently, because of the health benefits attributed to mate (Bracesco, Sanchez, Contreras, Menini, \& Gugliucci, 2011). In fact, yerba mate has been employed for the treatment of different pathologies in indigenous tribal medicine. In recent years, several of these pharmacological activities have been documented in scientific papers, demonstrating antioxidant, anti-inflammatory, anti-obesity, or cardioprotective effects, although its intake has also been correlated with certain types of cancer, specially of the oral cavity (Arçari et al., 2009; de Mejía, Song, Heck, \& Ramírez-Mares, 2010; Pimentel et al., 2013, Bravo et al., 2014; Baeza, Sarriá, Mateos, \& Bravo, 2016). Thus, intake of yerba mate has been related to oesophageal cancer, associated to the high temperature mate is traditionally consumed (Lubin et al., 2014). Recently, a Working Group of the International Agency for Research on Cancer (IARC) concluded that drinking any very hot beverage at above $65^{\circ} \mathrm{C}$ was "probably carcinogenic to humans". However, drinking mate that is not very hot was considered as "not classifiable as to its carcinogenicity to humans" (Loomis et al., 2016). In fact, mate intake was inversely associated with breast cancer risk in a case-control study developed in Uruguay (Ronco et al., 2016), among other studies.

In contrast, both in vitro and in vivo studies have shown health beneficial properties of yerba mate. The ingestion of mate tea can increase plasma and blood antioxidant protection in patients with dyslipidemia (Boaventura et al., 2012), improve biomarkers of lipid profile in healthy and dyslipidemic subjects (De Morais et al., 2009), reduce the atherogenetic effect of 
high-fat diets in animals (Bravo et al., 2014), and improve vascular endothelial function decreasing atherosclerotic risk factors in hyperlipidemic rats (Gao, Liu, Qu, \& Zhao, 2013). Yerba mate has also shown anti-obesity properties in high-fat diet-induced obese mice (Arçari et al., 2009), reducing both central and peripheral inflammation in diet-induced obese animals (Pimentel et al., 2013).

Indeed, yerba mate is an interesting source of bioactive compounds that might contribute synergistically or complementarily to the health benefits associated to its consumption. Yerba mate contains certain amount of methylxanthines, mainly caffeine $(0.32-0.86 \%$ dry matter basis) and minor amounts of theobromine (0.04-0.15\%) (Cardozo et al., 2007; Borré et al., 2010). Other interesting bioactive compounds are triterpenic saponins, constituted by triterpenoid aglycones (ursolic and oleanolic acids) with one or more sugar chains, which content amounts to $4 \%(\mathrm{w} / \mathrm{w})$ (Borré et al., 2010). However, most of the beneficial health effects attributed to yerba mate are related with its phenolic fraction, due to the antioxidant, anti-inflammatory and anti-carcinogenic effects as well as their capacity to regulate gene expression (Bravo, 1998). Polyphenols constitute $7-10 \%$ of the dry weight of yerba mate leaves (Bravo, Goya, \& Lecumberri, 2007), with antioxidant properties evaluated in vitro by FRAP and ABTS assays comparable to those of red wine or tea. Hydroxycinnamates, known as hydroxycinnamic acids and more collectively as chlorogenic acids, constitute the main polyphenols in yerba mate, accounting up to $95 \%$ of the phenolic content, the remaining $5 \%$ being flavonols (Bravo et al., 2007). Hydroxycinnamates are a family of esters formed between quinic acid and one or more hydroxycinnamic acids (caffeic, ferulic and coumaric acids). Caffeic acid is the main hydroxycinnamic moiety, forming mono- and dicaffeoylquinic acid isomers, which represent over $90 \%$ of the total phenolic content, with 5-caffeoylquinic acid (chlorogenic acid) as the main hydroxycinnamate in yerba mate. In addition, flavonols such as quercetin and kaempherol, mainly glycosylated, are present in the phenolic fraction of yerba mate (Bravo et al., 2007; Mateos, Baeza, Sarria, \& Bravo, submitted). 
In spite of the importance of understanding polyphenol bioavailability to know the concentration and chemical structure of the circulating bioactive metabolites and their contribution to the health effects of mate consumption, there is no in vivo study of the bioavailability of polyphenols in yerba mate in contrast to other popular beverages like coffee (Stalmach et al., 2009; Redeuil et al., 2011, among others) or tea (Rodríguez-Mateos et al., 2014). Therefore, the aim of the present work was to study the bioavailability of hydroxycinnamates and flavonols contained in yerba mate in healthy humans after consumption of a single serving of yerba mate tea following a targeted metabolomics approach.

\section{MATERIALS AND METHODS}

\subsection{Chemical reagents}

A commercial brand of mate or yerba mate, original from Argentina (Taragui), was purchased in a local supermarket in Madrid (Spain). All solvents and reagents were of analytical grade unless otherwise stated. Ascorbic acid, 5-caffeoylquinic acid, ferulic acid, caffeic acid, quercetin, kaempherol, rutin, 3,4-dihydroxyphenylpropionic acid, 4-hydroxy-3methoxyphenylpropionic acid, 4-hydroxyphenylpropionic acid, 3,4-dihydroxyphenylacetic acid, 4-hydroxyphenylacetic acid, 3,4-dihydroxyphenylbenzoic acid, and 4-hydroxyphenylbenzoic acid were acquired from Sigma-Aldrich (Madrid, Spain). 3,5-dicaffeoylquinic acid was purchased from PhytoLab (Vestenbergsgreuth, Germany). Methanol, formic acid, and acetonitrile (HPLC grade) were acquired from Panreac (Madrid, Spain).

\subsection{Phenolic characterization of yerba mate by HPLC}

The phenolic fraction of yerba mate was characterized in the beverage obtained after infusing $4.91 \mathrm{~g}$ of yerba mate in $250 \mathrm{~mL}$ boiling water for 5 minutes and filtering through a cloth strainer. Then, an aliquot of the mate infusion was filtered through a PVDF $0.45 \mu \mathrm{m}$ filter 
prior to injection on the HPLC system following the method previously described by Bravo et al (2007) with some modifications. Phenolic composition of yerba mate was analyzed using an Agilent 1200 series liquid chromatographic system equipped with an autosampler, quaternary pump and diode-array (DAD) detector. Separation was performed on a Superspher 100 RP18 column ( $250 \mathrm{~mm} \times 4.6 \mathrm{~mm}$ i.d., $4 \mu \mathrm{m}$, Agilent Technologies) preceded by an ODS RP18 guard column kept in a thermostatic oven at $30^{\circ} \mathrm{C}$. Each sample $(20 \mu \mathrm{L})$ was separated using a mobile phase consisting of $1 \%$ formic acid (solvent $\mathrm{A}$ ) and acetonitrile (solvent $\mathrm{B}$ ) at a flow rate of 1 $\mathrm{mL} / \mathrm{min}$. The solvent gradient changed from $10 \%$ to $20 \%$ solvent B over $5 \mathrm{~min}, 20 \%$ to $25 \%$ solvent B over $30 \mathrm{~min}, 25 \%$ to $35 \%$ solvent B over $10 \mathrm{~min}$, then maintained isocratically for 5 min, and returning to the initial conditions over $10 \mathrm{~min}$. Chromatograms were recorded at 320 and $360 \mathrm{~nm}$, which are the maxima wavelengths of absorbance of hydroxycinnamic acid derivatives and flavonols, respectively. For quantitative analysis the external standard method was used. Due to the lack of standards for certain phase II metabolites, they were tentatively quantified by using the calibration curves corresponding to their phenolic precursors. Thus, 5caffeoylquinic acid, caffeic acid, ferulic acid, 3,4-dihydroxyphenylpropionic acid, 4-hydroxy-3methoxyphenylpropionic acid, 4-hydroxyphenylpropionic acid, 3,4-dihydroxyphenylacetic acid, 4-hydroxyphenylacetic acid, 3,4-dihydroxyphenylbenzoic acid, and 4-hydroxyphenylbenzoic acid in addition to quercetin and kaempherol were used as standards to quantify the metabolites identified in both plasma and urine samples. Infusions were prepared and analyzed in triplicate and the results were expressed as the mean value.

\subsection{Subjects and study design}

The study protocol was conducted in accordance with the ethical recommendations of the Declaration of Helsinki and approved by the Ethics Committee of Hospital Universitario Puerta del Hierro-Majadahonda (Madrid, Spain). Volunteer recruitment was carried out through placing advertisements at the Institute of Food Science, Technology and Nutrition (ICTAN). 
The study was carried out in twelve healthy subjects ( 7 men and 5 women). Men's average age and body mass index were $27.86 \pm 3.48$ y and $23.42 \pm 2.52 \mathrm{~kg} / \mathrm{m}^{2}$, respectively, and women's $28.88 \pm 3.56$ y and $22.43 \pm 3.33 \mathrm{~kg} / \mathrm{m}^{2}$, respectively. They were non-smoker, nonvegetarian, non-pregnant women, who were not taking any medication or nutritional supplements, not suffering from any chronic pathology or gastrointestinal disorder. The sample size was estimated attending to similar previous bioavailability studies (Stalmach et al., 2009 and Mateos et al., 2016). The volunteers gave their informed consent prior to participation.

The study was carried out at the Human Nutrition Unit of ICTAN. After an overnight fast, volunteers consumed $4.91 \mathrm{~g}$ of yerba mate in $250 \mathrm{~mL}$ of boiling water, infused for 5 minutes and filtered through a cloth strainer. A polyphenol-free breakfast was provided $2 \mathrm{~h}$ after consuming the mate infusion; $4 \mathrm{~h}$ and $8 \mathrm{~h}$ later ( 6 and $10 \mathrm{~h}$ after mate intake, respectively) a polyphenol-free lunch and afternoon snack were also provided to the volunteers, who remained at the Human Nutrition Unit throughout the duration of the study. Water and isotonic beverages were available ad libitum. On the three days previous to the intervention, participants were instructed not to consume infusions (yerba mate, chamomile, etc.), coffee, tea, red wine or their derived products, whole grain cereals (white bread was allowed), as well as fruits, fruit juices and vegetables, except bananas, watermelon, cantaloupes and potatoes. In addition, consumption of legumes, virgin olive oil, vinegar and dried fruits was also restricted. Volunteers were asked to complete a $24 \mathrm{~h}$ food intake recall the day before the intervention in order to control any possible food restriction incompliance.

Prior to mate intake, a nurse inserted a cannula in the cubital vein of the non-prevailing arm of the volunteers and blood samples were collected into EDTA-coated tubes at baseline $(\mathrm{t}=0)$ and then at $0.5,1,1.5,2,3,4,5,6,8,9,10$, and $12 \mathrm{~h}$ after consuming the mate tea. Plasma was separated by centrifugation ( 10 minutes, $1500 \mathrm{~g}, 4^{\circ} \mathrm{C}$ ) and stored at $-80^{\circ} \mathrm{C}$ until further analysis. Urine samples were collected in $24 \mathrm{~h}$ urine collection containers containing 5 
$\mathrm{mg}$ of ascorbic acid at different time intervals ( $\mathrm{t}=-2-0,0-2,2-5,5-8,8-12,12-24 \mathrm{~h})$, aliquoted and frozen at $-20^{\circ} \mathrm{C}$ until analysis.

\subsection{Extraction of phenolic metabolites from biological samples}

A liquid-liquid extraction and protein precipitation with acetonitrile and methanol was used to isolate metabolites from plasma following the procedure described by Day, Mellon, Barron, Sarrazin, Morgan, \& Williamson, (2001) with some modifications. A $400 \mu \mathrm{L}$ defrosted plasma sample was acidified with $12 \mu \mathrm{L}$ of $50 \%(\mathrm{v} / \mathrm{v})$ aqueous formic acid. After vortexing the aqueous mixture, it was added drop wise to $1000 \mu \mathrm{L}$ of cold acetonitrile, containing $0.2 \mathrm{~g} / \mathrm{mL}$ ascorbic acid, and vortexed three times for $20 \mathrm{~s}$ before centrifuging at $10000 \mathrm{rpm}$ for $10 \mathrm{~min}$ at $4^{\circ} \mathrm{C}$. The supernatant was decanted, and the pellet was re-extracted with $1000 \mu \mathrm{L}$ of methanol. After centrifugation (10000 rpm, $10 \mathrm{~min}$ ), the two supernatants were combined and reduced to dryness under a stream of nitrogen at $30^{\circ} \mathrm{C}$. The dried samples were resuspended in $100 \mu \mathrm{L}$ of aqueous formic acid $(0.1 \% \mathrm{v} / \mathrm{v})$ containing $10 \%$ acetonitrile acidified with $0.1 \%$ formic acid and centrifuged at $4^{\circ} \mathrm{C}$ for $20 \mathrm{~min}$ at $14000 \mathrm{rpm}$. The final supernatant was collected, filtered $(0.45$ $\mu \mathrm{m}$ pore-size, cellulose-acetate membrane filters, Albet), and $20 \mu \mathrm{L}$ were analyzed by LC-MSQToF.

Urine samples were diluted with an equivalent volume of Milli-Q water and centrifuged at $14000 \mathrm{rpm}\left(10 \mathrm{~min}, 4^{\circ} \mathrm{C}\right)$. Supernatants were filtered $(0.45 \mu \mathrm{m}$ pore-size cellulose-acetate membrane filters) and a $5 \mu \mathrm{L}$ aliquot was directly injected into the LC-MS-QToF equipment.

\subsection{Metabolite identification by HPLC-ESI-QToF analysis}

Metabolites identification was developed by HPLC-ESI-QToF following the procedure by Mateos et al (2016) with minor modifications. Briefly, analysis were performed on an Agilent 1200 series LC system coupled to an Agilent 6530A Accurate-Mass Quadrupole Time-of-Flight (Q-ToF) with ESI-Jet Stream Technology (Agilent Technologies). Compounds were separated on 
a reverse-phase Ascentis Express C18 $(15 \mathrm{~cm} \times 3 \mathrm{~mm}, 2.7 \mu \mathrm{m})$ column (Sigma-Aldrich Química, Madrid) preceded by a Supelco $55215-\mathrm{U}$ guard column at $30^{\circ} \mathrm{C}$. The test samples, either $30 \mu \mathrm{L}$ of plasma or $5 \mu \mathrm{L}$ of urine, were injected and separated by using a mobile phase consisting of water (phase A) and acetonitrile (phase B), both containing $0.1 \%$ formic acid, at a flow rate of $0.3 \mathrm{~mL} / \mathrm{min}$. The mobile phase was initially programmed with $90 \%$ of solvent $\mathrm{A}$ and $10 \%$ of $\mathrm{B}$. The elution program increased to $30 \%$ of solvent B in $10 \mathrm{~min}, 40 \%$ of solvent B in $5 \mathrm{~min}$, and $50 \%$ of solvent B in $5 \mathrm{~min}$. Then, the initial conditions ( $10 \%$ of solvent B) were recovered in 2 min and maintained for 8 min. The Q-ToF acquisition conditions were as follows: drying gas flow (nitrogen, purity $>99.9 \%$ ) and temperature were $10 \mathrm{~L} / \mathrm{min}$ and $325^{\circ} \mathrm{C}$, respectively; sheath gas flow and temperature: $6 \mathrm{~L} / \mathrm{min}$ and $250^{\circ} \mathrm{C}$, respectively; nebulizer pressure: $25 \mathrm{psi}$; cap voltage: $3500 \mathrm{~V}$; nozzle voltage: $500 \mathrm{~V}$. Mass range selected was from 100 up to $970 \mathrm{~m} / \mathrm{z}$ in negative mode and fragmentor voltage of $150 \mathrm{~V}$. Data were processed by using Mass Hunter Workstation Software. Due to the lack of standards for some phase II metabolites, they were tentatively quantified by using the calibration curves corresponding to their phenolic precursors.

Thus, 5-caffeoylquinic acid was used to quantify monohydroxycinnamoyl derivatives; caffeic, ferulic, dihydrocaffeic, dihydroferulic, and dihydrocoumaric acids were used to quantify their respective free hydroxycinnamic acids and phase II metabolites, and quercetin to quantify phase II derivatives of flavonols. The rest of microbial metabolites identified, derivatives of hydroxyphenylpropionic, hydroxyphenylbenzoic and hydroxybenzoic acids, were quantified using their respective commercially available standards. Urine results were normalized by the volume excreted in each studied interval.

\subsection{Nutrikinetic analysis}

Statistical analyses were carried out using the program SPSS (version 19.0, SPSS, Inc., IBM Company). To determine the absorption and elimination of hydroxycinnamic metabolites after 
consumption of the yerba mate infusion, metabolite nutrikinetics were studied using the pharmacokinetic functions of Microsoft Excel. Maximum concentration $\left(C_{\max }\right)$, area under curve $(A \cup C)$ and time to reach maximum concentration $\left(T_{\max }\right)$ were calculated. Data are given as mean \pm standard deviation.

\section{RESULTS}

\subsection{Phenolic content of yerba mate tea}

The phenolic constituents present in yerba mate were monitored by diode-array detection. The $250 \mathrm{~mL}$ serving of yerba mate infusion prepared from $4.91 \mathrm{~g}$ of mate leaves contained $1118 \mu \mathrm{mol}(396 \mathrm{mg}$ ) hydroxycinnamic acids. The most abundant phenolic compounds in yerba mate were monoacylquinic acids, especially caffeoylquinic acids $(55.2 \%$ of the total polyphenols in mate), followed by dicaffeoylquinic acids (27.8\%). Minor amounts of other mono- and diacylquinic acids were also detected (i.e. feruloylquinic, coumaroylquinic, and caffeoylferuloylquinic acids), with noticeable contents of caffeoylglucose isomers (4.3\% of total polyphenols) and caffeoylquinic lactones (3.4\%). Finally, flavonols (rutin and kaempherolrhamnoglucoside) were also present in minor amounts ( $4.1 \%$ of the total phenols quantified in mate tea) (Table 1).

\subsection{LC-QToF identification of hydroxycinnamate and metabolites in plasma and urine}

Table 2 shows the retention time (RT), molecular formula, accurate mass of the molecular ion $[\mathrm{M}-\mathrm{H}]^{-}$after negative ionization, and $\mathrm{MS}^{2}$ fragments of the main compounds identified in plasma and urine by LC-QToF, and also summarizes all the identified compounds, which characterization was supported by commercial standards and/or previously published results.

In urine, unmetabolized hydroxycinnamoylquinic acids were detected, such as 3- and 5caffeoylquinic acids in addition to 3-, 5- and 4-feruloylquinic acid, whereas coumaroylquinic acid was detected in both plasma and urine samples. 
A minor group of metabolites corresponded to hydroxycinnamic acids derived from hydrolysis of hydroxycinnamate, which were extensively metabolized into phase II derivatives. In particular, caffeic acid 3-sulfate, isoferulic acid and ferulic acid 4-sulfate were identified in both plasma and urine. Moreover, ferulic acid 4-glucuronide and isoferulic acid 3-glucuronide were identified in urine, while glucuronidated ferulic acid could only be detected in plasma.

It is important to note the presence in urine samples of a metabolite related with caffeoylquinic lactone, in particular caffeoylquinic lactone sulfate (Table 2).

Another important group of metabolites identified corresponded to reduced forms of hydroxycinnamic acids, which were extensively transformed into phase II derivatives. Among these metabolites were dihydrocaffeic acid, in both plasma and urine, dihydrocaffeic acid 3glucuronide, only in urine, and two sulfated isomers identified as dihydrocaffeic acid 4-sulfate and dihydrocaffeic acid 3-sulfate, also in urine, although dihydrocaffeic acid 4-sulfate was also detected in plasma. Two isomers of dihydroferulic acid, detected in plasma and urine, were identified as trans- and isodihydroferulic acids based on available standards. Furthermore, glucuronidated and sulfated iso- and trans-dihydroferulic acids were identified in both plasma and urine. Related with coumaric acid, dihydrocoumaric acid was identified based on the commercial standard, as well as its glucuronidated and sulfated derivatives in urine. The identification of phase II metabolites was based on previous studies carried out using coffee with similar phenolic composition (Redeuil et al., 2011, Gómez-Juaristi, Martínez, Sarriá, Bravo, \& Mateos, submitted).

To the best of our knowledge, a new group of reduced forms resulting from the microbial metabolism of hydroxycinnamates, namely dihydrohydroxycinnamoylquinic acids, had not been described before. An isomer of dihydrocaffeoylquinic acid at $8.5 \mathrm{~min}$ has been characterized based on its MS spectrum, quasimolecular ion at $m / z 355.1035$ and fragment ion at $m / z$ 181. This metabolite was detected in urine and was identified as $3-$ dihydrocaffeoylquinic acid, based on a previous in vivo bioavailability studies using coffee 
polyphenols carried out in our research group, (Gómez-Juaristi et al., submitted). Moreover, two isomers of dihydroferuloylquinic and dihydrocoumaroylquinic acids have been identified in both plasma and urine. 3- and 5-dihydroferuloylquinic acids eluted at 15.1 and $15.4 \mathrm{~min}$, respectively, with common MS spectra $\left([\mathrm{M}-\mathrm{H}]^{-}\right.$at $\mathrm{m} / \mathrm{z} 369.1191$ and fragment ion at $\mathrm{m} / \mathrm{z} 195$ corresponding to dihydroferulic acid), whilst two other isomers of dihydrocoumaroylquinic acid were assigned to peaks eluting at 14.8 and $15.3 \mathrm{~min}$, based on their MS spectra, with quasimolecular ion at $\mathrm{m} / \mathrm{z} 339.1085$ and fragment ion at $\mathrm{m} / \mathrm{z} 165$, corresponding to dihydrocoumaric acid.

Feruloylglycine was detected in urine previously reported by Stalmach et al., (2009). However, two chromatographic peaks at RT 8.8 and 9.5 min showed a chemical structure compatible with this compound, [M-H] $]^{-}$at $m / z 250.0721$ and fragment ions at $m / z 191$ and 134, being tentatively assigned as feruloylglycine and isoferuloylglycine, respectively, according to the order of elution of their precursors (ferulic and isoferulic acids). While feruloylglycine was detected in both plasma and urine, isoferuloylglycine was detected only in urine.

Regarding flavonols present in yerba mate, two phase II metabolites were identified in plasma and urine after mate consumption. The first metabolite corresponded to methylquercetin-glucuronide and the second to kaempherol-glucuronide.

Lastly, derivatives of hydroxyphenylpropionic, hydroxyphenylacetic, hydroxybenzoic and hydroxyhipuric acids were also characterized in plasma and urine samples.

\subsection{Quantification of plasma metabolites and nutrikinetic parameters}

Of the 45 metabolites identified after mate consumption, 31 were detected in plasma although only 16 showed levels above limit of quantification. The kinetic of plasma appearance and clearance of these metabolites up to $12 \mathrm{~h}$ post-intake are represented in Figure 1. Nutrikinetic parameters are summarized in Table 3. 
Coumaroylquinic acid was the only non-metabolized compound detected in plasma, at trace levels (Table 3). Three phase II derivatives of hydroxycinnamic acids were also identified in plasma: caffeic acid 3-sulfate, ferulic acid 4-glucuronide and ferulic acid 4-sulfate, with similar kinetic profile characterized by a rapid increase of their concentrations between 1 and $2 \mathrm{~h}$ after mate consumption and slow clearance, maintaining or even showing a second maximum between 4 and $5 \mathrm{~h}$ for the particular case of ferulic acid 4-sulfate and ferulic acid 4glucuronide, and subsequent clearance at 10-12 h post-intake (Figure $1 \mathrm{~A}$ ). These compounds were present in low concentrations in plasma, showing $C_{\max }$ ranging from 11 to $37 \mathrm{nM}$ (Table 3). The time to reach maximum concentration $\left(T_{\max }\right)$ ranged between 0.6 and $2.1 \mathrm{~h}$, which pointed to absorption taking place in the small intestine.

Reduced forms of hydroxycinnamic acids, dihydroferulic acid (Figure 1B), dihydrocaffeic and dihydroisoferulic acids (Figure 1C) and their phase II derivatives (dihydrocaffeic acid 4-sulfate, dihydroferulic acid 4-glucuronide, dihydroisoferulic acid 3-glucuronide, dihydroferulic acid 4sulfate and dihydroisoferulic acid 3-sulfate, Figure 1D) constitute the main group of metabolites detected in plasma. The plasmatic profile of these metabolites showed maximum concentrations between 5.7 and $7.5 \mathrm{~h}\left(\mathrm{~T}_{\max }\right)$ post-intake and minor second maxima between 8 and $9 \mathrm{~h}$, compatible with a biphasic kinetic. Dihydroferulic acid and dihydrocaffeic acid 4sulfate were the predominant metabolites, showing $C_{\max }$ values of 306 and $188 \mathrm{nM}$, respectively, followed by sulfated and glucuronidated derivatives of ferulic acid with $C_{\max }$ ranging from 84 to $56 \mathrm{nM}$. Dihydrocaffeic acid, dihydroisoferulic and its phase II (sulfated and glucuronidated) metabolites were less abundant, with $C_{\max }$ values ranging from 52 to $27 \mathrm{nM}$.

Feruloylglycine, as a ferulic acid derivative, has been detected with kinetic profile similar to that of the reduced forms of hydroxycinnamic acids (Figure 1C), since its concentration rapidly increased at $6 \mathrm{~h}\left(\mathrm{~T}_{\max } 6.3 \mathrm{~h}\right.$ ) and afterwards decreased slowly. In common with the reduced hydroxycinnamates, basal levels were not recovered $12 \mathrm{~h}$ after mate intake. The presence in plasma was relatively low $\left(\mathrm{C}_{\max } 33 \mathrm{nM}\right.$, Table 3$)$. 
We also identified for the first time reduced forms of hydroxycinnamate esters in plasma: 3- and 5-dihydroferuloylquinic acids, and two isomers of dihydrocoumaroylquinic acid. These compounds showed the most delayed kinetic of all the mentioned metabolites, with maxima concentration about $9 \mathrm{~h}\left(\mathrm{~T}_{\max } 8.9-9.1 \mathrm{~h}\right.$ ) and partial clearance after $12 \mathrm{~h}$ post-intake (Figure 1E). Among these microbial metabolites, 5-dihydroferuloylquinic acid was the most abundant $\left(C_{\max }\right.$ $47 \mathrm{nM}$ ), followed by 3-dihydroferuloylquinic acid and the two isomers of dihydrocoumaroylquinic acids with $C_{\max }$ values ranging from trace levels to $22 \mathrm{nM}$ (Table 3).

Finally, phase II derivatives of flavonols were detected in plasma after yerba mate intake, namely kaempherol-glucuronide (Figure $1 F$ ) and trace amounts of methyl-quercetinglucuronide. Kaempherol-glucuronide showed maximum concentration $4 \mathrm{~h}$ after mate consumption and was quickly cleared $8 \mathrm{~h}$ post-intake. Flavonol metabolites were among the least abundant of all the identified plasma metabolites $\left(C_{\max } 12 \mathrm{nM}\right)$, showing kinetics matching with colonic formation ( $\left.T_{\max } 4 \mathrm{~h}\right)$.

Although hydroxyphenylpropionic, hydroxyphenylacetic and hydroxybenzoic acids metabolites were also detected in plasma, no differences were observed in their concentration during the $12 \mathrm{~h}$ blood sampling after yerba mate intake (data not shown), posing doubts on the contribution of mate to the presence of these simple phenols in plasma.

\subsection{Quantification of urinary metabolites}

Table 4 shows the metabolites quantified in $24 \mathrm{~h}$ urine samples of the healthy volunteers after consumption of yerba mate. Thirty-three metabolites were quantified in urine, including 15 new metabolites detected in urine but not in plasma; in contrast, dihydroisoferulic acid, which was quantified in plasma, was not detected in urine. These metabolites and their phase Il derivatives could be discriminated as resulting from absorption at the small intestine or after colonic metabolism. In addition, 11 metabolites, including derivatives of hydroxyphenylpropionic, hydroxyphenylacetic, hydroxybenzoic, hydroxyhipuric acids and 
floroglucinol, were also characterized in urine (Table 4). Most of these microbial metabolites were present in basal urine samples, their levels minimally increasing during the $24 \mathrm{~h}$ sampling period. Since these compounds are also involved in other biotransformation pathways and taking into account their low total excretion (about $11.21 \mu \mathrm{mol}$ in $24 \mathrm{~h}$ ), they were not considered to determine the total recovery of yerba mate phenolic metabolites.

Monoacylquinic acids (3- and 5-caffeoylquinic acids, 3-, 4- and 5-feruloylquinic acids, and coumaroylquinic acid) were excreted in small amounts in urine (up to $1.6 \%$ of the total quantified metabolites), showing direct intestinal absorption and excretion of non-metabolized hydroxycinnamate esters (Table 4). Of this fraction, feruloylquinic acids were the most abundant compounds in urine ( $87.5 \%$ of intestinal metabolites). Bearing in mind the fact that yerba mate tea contained mostly caffeoylquinic acids and only minor amounts of feruloylquinic acids (Table 1), it can be hypothesized that part of the excreted feruloylquinic acids result from phase II metabolism (i.e. methylation by catechol-O-methyl transferase, COMT). Noticeably, caffeoylquinic lactone was also detected in urine (up to $116 \mathrm{nmol}$ in $24 \mathrm{~h}$ urine) as a sulfated metabolite, showing the intestinal absorption and phase II metabolism of this hydroxycinnamate (Table 4).

However, hydroxycinnamic esters absorbed at the intestinal level were preferentially hydrolyzed by cellular esterases yielding hydroxycinnamic acids that were metabolized by phase II enzymes (sulfated and glucuronidated). These compounds, along with free isoferulic acid, accounted for $11.8 \%$ of the total metabolites excreted. Caffeic acid 3-sulfate and ferulic acid 4-sulfate were the most abundant hydroxycinnamic acids, with urinary excretions as high as 4.8 and $8.1 \mu \mathrm{mol}$ in $24 \mathrm{~h}$ urine, respectively (Table 4 ).

All these metabolites were preferentially excreted between 2 and $4 \mathrm{~h}$ after mate intake, in total amounting $20.12 \mu \mathrm{mol}$ in $24 \mathrm{~h}$ (13.4\% of the total metabolites excreted). It is worth noting that glucuronidated and sulfated ferulic acids were also largely excreted between 8 and $12 \mathrm{~h}$, in agreement with the biphasic kinetic observed in plasma (Figure $1 \mathrm{~A}$ ). 
In accordance with that observed for the metabolites absorbed at the small intestinal level, colonic reduced dihydrohydroxycinnamic acids were largely metabolized into their phase II derivatives (Table 4). Excretion of dihydrocaffeic acid and its phase II metabolites added up to $43.12 \mu \mathrm{mol}$ in $24 \mathrm{~h}$, dihydrocaffeic acid 3-sulfate being the major urinary metabolite (38.78 $\mu \mathrm{mol})$. Similarly, excretion of dihydroferulic acid and its phase II derivatives amounted up to $41.27 \mu \mathrm{mol}$ in $24 \mathrm{~h}$. As mentioned above, ingestion of caffeoylquinic acids with mate tea was much higher than that of feruloylquinic acids (218.5 vs $15.7 \mathrm{mg}$ ), again pointing to the extensive methylation of the caffeoyl moiety. Finally, excretion of dihydrocoumaric acid and its sulfated and glucuronidated metabolites amounted to $10.02 \mu \mathrm{mol}$ in $24 \mathrm{~h}$, in accordance with the lower presence of coumaroylquinic acids in the yerba mate infusion.

It is worth noting that sulfation was the predominant phase II transformation of reduced dihydrocinnamic acids, since total excretion of sulfated metabolites amounted to $72.26 \mu \mathrm{mol}$ in contrast with $11.95 \mu \mathrm{mol}$ of glucuronidated molecules.

Importantly, reduced forms of hydroxycinnamate esters were also characterized in urine. 3dihydrocaffeoylquinic acid, 3- and 5-dihydroferuloylquinic acids and two isomers of dihydrocoumaroylquinic acid were quantified in noticeable amounts, accounting for $5.6 \%$ of total urinary metabolites. These compounds showed a delayed excretion and were eliminated in urine between 8 and $12 \mathrm{~h}$ after yerba mate intake, in agreement with their delayed appearance in plasma (Figure 1E).

Feruloylglycine and isoferuloylglycine were also extensively excreted in urine. Their contribution to the total amount of identified metabolites was highly significant (17.6\%), mainly constituted by feruloylglycine $(25.77 \mu \mathrm{mol}$ in $24 \mathrm{~h})$.

Finally, phase II derivatives of flavonols were also excreted in urine, mainly kaempherolglucuronide peaking at the $4-8 \mathrm{~h}$ interval. In spite of their relative abundance in mate tea, flavonol metabolites only comprised $0.18 \%$ of the total urinary metabolites, pointing to a very low bioavailability of these flavonoids in contrast to hydroxycinnamic acids. 
It has to be noted that no diacylquinic acids were identified in urine (or plasma) samples, in spite of the high amounts of these compounds in mate tea, specially dicaffeoylquinic acids (Table 1).

In conclusion, the total amount of metabolites derived from hydroxycinnamates and flavonols in yerba mate that were excreted in the $24 \mathrm{~h}$ urine collected after the intake of a single serving of this beverage added up to $149.6 \mu \mathrm{mol}$ (Table 4), corresponding to $13.4 \%$ of the $1118 \mu \mathrm{mol}$ polyphenols consumed.

\section{Discussion}

The health properties associated to yerba mate, mainly related to its high phenolic content, points to the importance of advancing in the knowledge of the bioavailability of mate polyphenols in humans, being highly relevant to identify the circulating metabolites with potential biological activity.

Although yerba mate is extensively consumed mostly in Latin America, the bioavailability of mate polyphenols had not been previously addressed. In the present study we report the absorption and metabolism of mate phenolic compounds by healthy individuals after the consumption of a single serving of yerba mate prepared as an infusion. The preparation of the beverage followed procedures common for other herbal teas (i.e. infusion of mate leaves in boiling water), rendering a beverage known as "mate cocido" that differs from traditional consumption patterns in most Latin American countries (i.e. continuous addition of very hot water to a big amount of mate leaves in a special recipient called "Calabaza", drinking the beverage several times until complete extraction of flavor compounds). This mate infusion contained $396 \mathrm{mg}(1118 \mu \mathrm{mol})$ of polyphenols, mostly hydroxycinnamate esters with lower amounts of flavonols.

Results showed that mate polyphenols were partially absorbed and extensively metabolized, mostly by the colon microbiota. Thus, reduced forms of hydroxycinnamic acids 
(dihydrohydroxycinnamic acids), mainly as the phase II conjugated metabolites formed after absorption in the colon, were the predominant metabolites in plasma and urine, underlying the importance of the microbiota on the metabolism of hydroxycinnamic compounds.

However, direct absorption of hydroxycinnamate esters takes place in the small intestine, as confirmed by the presence of caffeoylquinic, feruloylquinic and coumaroylquinic acids in urine, peaking at short times after mate intake (2-4 h), yet in low proportion compared to other excreted metabolites ( $1.6 \%$ of the total phenolic derivatives in urine). Also, trace amounts of coumaroylquinic acid were detected in plasma (Table 3). Although these compounds were excreted un-metabolized, the relatively high amount of feruloylquinic acid in relation with caffeoylquinic acid suggests extensive methylation of the later in view of the higher content of caffeoylquinic acid in the mate tea (Table 1). In line with this, the presence in urine of small amounts of caffeoylquinic lactone shows the ability of hydroxycinnamate esters to be conjugated by phase II enzymes.

Although in relatively low amounts compared to the total excretion of phenolic metabolites (11.77\%) hydroxycinnamic acids like isoferulic acid, together with phase II metabolites of caffeic, ferulic and isoferulic acids were more abundant in urine than the non-metabolized hydroxycinnamate esters, suggesting hydrolysis by esterases present in the wall of the small intestine (Andreasen, Kroon, Williamson, \& Garcia-Conesa, 2001), releasing hydroxycinnamic acids (caffeic, ferulic, and coumaric acids) from their respective hydroxycinnamates, which subsequently were metabolized by action of phase II enzymes (COMT, sulfotransferases and UDP-glucuronosyl transferases) to enter the bloodstream (Figure 2). It is worth noting that no free dicaffeoylquinic and caffeoylferuloylquinic acids were detected in the biological samples. Biotransformation of these diacylquinic acids would involve initial hydrolysis by intestinal esterases (Figure 2), with no direct absorption of the diacyl esters. The fact that the main intestinal metabolites quantified in plasma were sulfated and glucuronidated caffeic and 
ferulic acids supports the prevalent intestinal absorption of hydroxycinnamic acids over hydroxycinnamate esters.

As mentioned above, part of the ferulic acid metabolites would derive from the hydrolysis of feruloylquinic and caffeoylferuloylquinic acids present in yerba mate, but most came from the methylation of caffeic acid by COMT, considering the relative ratio caffeic/ferulic acids derivatives in mate compared to biological samples.

Hydroxycinnamates (caffeoyl-, feruloyl-, and coumaroylquinic acids), hydroxycinnamic acids, their phase II derivatives along with caffeoylquinic lactones quickly $\left(T_{\max } 0.6-2.1 \mathrm{~h}\right.$ ) reached plasma $C_{\max }(11-37 \mathrm{nM})$ and were mainly excreted in urine between 2-4 $\mathrm{h}$ after mate ingestion, accounting for $13.5 \%$ of the metabolites excreted in urine after yerba mate consumption. The pharmacokinetic parameters of these compounds were compatible with their partial absorption in the small intestine. It is important to note that plasmatic concentration of phase II derivatives of hydroxycinnamic acids reached basal levels after 8-10 $\mathrm{h}$, whereas sulfated and glucuronidated derivatives of ferulic acid showed a second less intense maximum in their plasmatic profile. Likewise, the urinary excretion of sulfated and glucuronidated ferulic acid was higher between 4 and $12 \mathrm{~h}$, in agreement with the second maxima observed in plasma. This outcome may be related with enterohepatic recirculation, so that compounds absorbed in the small intestine reach the liver and are excreted in the bile, being recycled back to the small intestine and re-absorbed (Rodríguez-Mateos et al., 2014). Likewise, hydroxycinnamates not absorbed in the small intestine pass into the large intestine, where they may be hydrolyzed into free hydroxycinnamic acids by colonic esterases and then partially absorbed and metabolized into phase II derivatives before entering the circulation. The first pathway could explain why one compound can appear in plasma under different potentially bioactive forms whereas both pathways would justify the longer permanence of polyphenols in the body, and therefore the extended bioactivity. 
In all, the low levels in plasma and urine of metabolites of hydroxycinnamic acids and hydroxycinnamate esters confirm their low bioavailability in the upper gastrointestinal tract. Therefore, most of the ingested mate phenolic compounds would reach the large intestine, where they would be metabolized by the colonic microbiota. Considering the importance of the colon in the metabolism of polyphenols, already addressed in the literature (Del Río, Rodríguez-Mateos, Spencer, Tognolini, Borges, \& Crozier, 2013; Rodríguez-Mateos et al., 2013, among others), searching for microbial metabolites allowed characterizing a huge group of compounds derived from the reduction of hydroxycinnamic acids by the action of the gut microbiota. Thus, dihydrocaffeic, dihydroferulic and dihydrocoumaric acids and their phase II metabolites accounted for $63.1 \%$ of the total metabolites excreted in urine. In agreement with their colonic origin, this group of metabolites showed delayed kinetic parameters, with $T_{\max }$ values between 5.7 and $6.7 \mathrm{~h}$ in plasma ( $C_{\max }$ ranging between $27-306 \mathrm{nM}$ ) and peak urinary excretion 4-12 $\mathrm{h}$ after intake (Tables 3 and 4 ).

Another microbial metabolite derived from ferulic acid extensively excreted in urine was feruloylglycine, which was also detected in plasma (33 nM). This, together with isoferuloylglycine (only detected in urine in low amounts), was formed by the action of CoA enzyme. Feruloylglycine has already been reported in other studies after the consumption of coffee rich in hydroxycinnamic acids, although only in urine (Stalmach et al., 2009; Stalmach, Williamson, \& Crozier, 2014). Therefore, to our knowledge this is the first time feruloylglycine is reported in plasma, being also described for the first time the presence of isoferuloylglycine in urine after consumption of a hydroxycinnamate-rich beverage. It is important to note that the high amount of feruloylglycine excreted, $25.8 \mu \mathrm{mol}$ in $24 \mathrm{~h}$, makes it the second most abundant metabolite after dihydrocaffeic acid 3-sulfate (38.8 $\mu \mathrm{mol}$ in $24 \mathrm{~h})$. Consequently, the presence in urine of dihydrocaffeic acid-3-sulfate and feruloylglycine could be a very sensitive biomarker of yerba mate intake, since the excreted amount of both metabolites represented $25.9 \%$ and $17.6 \%$ of the ingested polyphenols, respectively. 
Another important contribution of the present work was the identification in biological fluids of dihydroderivatives of monoacylquinic acids, namely dihydrocaffeoyl-, dihydroferuloyland dihydrocoumaroylquinic acids (Tables 3 and 4). Only a previous in vitro study on the biotransformation of chlorogenic acid by human colonic microbiota reported the formation of dihydrocaffeoylquinic acid (Tomás-Barberán et al., 2014). In the present in vivo bioavailability study, relevant amounts of dihydromonoacylquinic acids were detected in plasma $\left(C_{\max } 19-47\right.$ $\mathrm{nM})$ and urine $(8.36 \mu \mathrm{mol}$ excreted in $24 \mathrm{~h})$. These compounds showed the latest kinetics of all the characterized metabolites, peaking in plasma $9 \mathrm{~h}$ after mate consumption and being excreted in urine between 8 and $12 \mathrm{~h}$ post-intake, amounting to $5.6 \%$ of the total urinary metabolites.

Mate also contains small amounts of flavonols $(4.1 \%$ of the total phenolic compounds, Table 1), mainly rutin (quercetin-rhamnoglucoside) and kaempherol-rhamnoglucoside. It is well known that flavonoid rhamnoglucosides cannot be absorbed by human enterocytes, being necessary their hydrolysis by microbial rhamnoglucosidases prior to absorption of the aglycone of the flavonoid-glucoside, since the human intestine lacks this enzyme. This explains the delayed kinetics ( $T_{\max } 4-5 \mathrm{~h}$ ) of the only two flavonol metabolites detected in very low amounts $(<12 \mathrm{nM}$ ) in plasma (Table 3 ), and their maximum urinary excretion at $4-8 \mathrm{~h}$ after mate intake (Table 4). The aglycones released in the colon undergone phase II conjugation in the liver into glucuronidated and methyl-glucuronidated metabolites before entering the circulation. These represented less than $0.2 \%$ of the total metabolites excreted in urine, pointing to a very low bioavailability of mate flavonols. However, it cannot be ruled out that kaempherol and quercetin would have been subjected to ring fission, resulting in the production of hydroxyphenylacetic acid catabolites.

It is important to highlight that microbial metabolites of hydroxycinnamates, mainly dihydrocaffeic acid, has proved to be as effective as the non-metabolized chlorogenic acids protecting human cells from oxidative stress (Baeza et al., 2016). Also, both dihydrocaffeic acid 
and dihydroferulic acid, the major metabolite in plasma (Table 3), were more effective than their phenolic precursors inhibiting platelet activation (Baeza, Bachmair, Wood, Mateos, Bravo, \& de Roos, 2017). Therefore, microbial metabolism of ingested hydroxycinnamates will contribute not only to increase their bioavailability and prolong their permanence in our body, but will also increase the biological activity of the phenolic fraction of mate, thus decisively contributing to tits health beneficial effects.

A limitation of the present study was the reduced collection of urine samples. Only flavonol metabolites and some hydroxycinnamate esters and hydroxycinnamic acid metabolites were completely excreted within the $24 \mathrm{~h}$ after mate intake. Most of the microbial metabolites showed relevant amounts in the 12-24 $\mathrm{h}$ interval, not returning to basal levels. It would have been interesting prolonging urine collection for at least further $24 \mathrm{~h}$ or until basal excretion levels were obtained to ascertain total recovery of phenolic metabolites. Therefore, an underestimation of the actual excreted metabolites and therefore of the bioavailability of mate polyphenols cannot be ruled out. Another limitation was the lack of some metabolite standards, mainly phase II derivatives, forcing us to express the results as equivalents of the corresponding precursor compound. Therefore, the results here indicated did not accurately measure the concentrations of these metabolites in the biological samples. However, the results are in line with other studies on the bioavailability of coffee hydroxycinnamates (Stalmach et al., 2009; Stalmach et al., 2014).

In all, total excretion of metabolites in urine, excluding metabolites which origin was not considered to be exclusively derived from the biotransformation of hydroxycinnamic acids such as hydroxyphenylacetic, hydroxyphenylpropionic and hydroxybenzoic acids, resulted in a recovery of just $13.4 \%$ of the phenols ingested with yerba mate. This shows a very low bioavailability of mate polyphenols. Bioavailability studies with coffee, which also contains hydroxycinnamate esters, show that coffee polyphenols are apparently more bioavailable than mate phenolics, recovering up to $30 \%$ of the ingested doses after coffee consumption 
(Stalmach et al., 2009). In accordance with the results of the present work, early plasma metabolites appeared in $\mu \mathrm{M}-\mathrm{nM}$ concentrations about 1-1.5 $\mathrm{h}$ after coffee intake, mostly as conjugated caffeic and ferulic acids (Stalmach et al., 2009; Redeuil et al., 2011). Similarly, dihydrocaffeic and dihydroferulic acids, mainly as phase II derivatives, reached $\mu \mathrm{M}$ concentrations in plasma 5-10 h after coffee intake (Gomez-Juaristi, 2015; Stalmach et al., 2009).

As mentioned before, the procedure followed to prepare the mate infusion (mate cocido) differed from traditional patterns in South America (calabaza). Therefore, the results here reported would be representative of occidental consumption patterns of herbal teas (here mate tea). Likely, differences could be expected in the nutrikinetic parameters when mate is consumed in a single serving or continuously during the day as is a common practice in South America. It has also to be noted that changes in the colonic microbiota could have happened in habitual consumers as an adaptation to mate drinking. In turn, in the present study volunteers consumed mate for the first time. Bearing in mind the importance of the colonic microbiota on the metabolism of mate polyphenols as observed in the present study, quantitative and/or qualitative differences in the reported colonic microbial metabolites among habitual and occasional consumers cannot be ruled out. Therefore, it would be most interesting to perform a bioavailability study in habitual mate consumers and compare results with those reported in the present work. Also, comparing microbiota of both habitual and occasional mate drinkers would be of great interest to gain insight into the potential adaptation of colonic microorganisms to dietary exposures to predominant sources of polyphenols.

\section{Conclusion}

This first study of the bioavailability and nutrikinetics of hydroxycinnamates and flavonols contained in yerba mate consumed by healthy humans show that polyphenols were partially absorbed and extensively metabolized. The predominant metabolites were phase II derivatives 
of reduced forms of hydroxycinnamic acids together with feruloylglycine. Other metabolites detected in decreasing order of abundance were dihydrohydroxycinnamic acids, hydroxycinnamic acids and their phase II derivatives, reduced forms of hydroxycinnamates, identified for the first time in an in vivo bioavailability study, hydroxycinnamates, and phase II derivatives of flavonols. Attending to their high urinary elimination, dihydrocaffeic acid-3sulfate and feruloylglycine can be proposed as biomarkers of intake of hydroxycinnamate-rich foods. In conclusion, biovailability of hydroxycinnamates and flavonols in yerba mate was low, with extensive metabolization mostly by the colonic microbiota, prolonging the permanence of bioactive metabolites in our body.

\section{Acknowledgements}

We are grateful to volunteers participating in the study. Authors thank I. Alvarez and M.A. Martinez at the Analytical Techniques Service (USTA) facilities of ICTAN for technical assistance on mass spectrometry analyses. We also are grateful to the Spanish Ministry of Economy and Competitivity (MINECO-FEDER) for financial support (projects AGL2010-18269 and AGL201569986-R). S.M.-L. was a predoctoral fellow of the JAE Program (JAEPre097) co-funded by CSIC and the European Social Fund. M. G.-J. was a predoctoral FPI fellow (BES2008-007138) of the Spanish Ministry of Science and Innovation. All authors revised and approved the final version of the manuscript.

The authors declare no conflicts of interest.

\section{References}

Andreasen, M. F., Kroon, P. A., Williamson, G., \& Garcia-Conesa, M. T. (2001). Esterase activity able to hydrolyze dietary antioxidant hydroxycinnamates is distributed along the intestine of mammals. Journal of Agricultural and Food Chemistry, 49, 5679-5684.

Arçari, D. P., Bartchewsky, W., dos Santos, T. W., Oliveira, K. A., Funck, A., Pedrazzoli, J., de Souza, M. F., Saad, M. J., Bastos, D. H., Gambero, A., Carvalho, Pde O., \& Ribeiro, M. L. 
(2009). Antiobesity effects of yerba maté extract (llex paraguariensis) in high-fat dietinduced obese mice. Obesity, 17, 2127-2133.

Boaventura, B. C., Pietro, P. F., Stefanuto, A., Klein, G. A., de Morais, E. C., de Andrade, F., Wazlawik, E., da Silva, E. L. (2012). Association of mate tea (Ilex paraguariensis) intake and dietary intervention and effects on oxidative stress biomarkers of dyslipidemic subjects. Nutrition, 28, 657-664.

Borré, G. L., Kaiser, S., Pavei, C., da Silva, F. A., Bassani, V. L., \& Ortega, G. G. (2010). Comparison of methylxanthine, phenolics and saponin contents in leaves, branches and unripe fruits from Ilex paraguariensis A. St.-Hil (mate). Journal of Liquid Chromatography \& Related Technologies, 33, 362-374.

Bracesco, N., Sanchez, A., Contreras, V., Menini, T., \& Gugliucci, A. (2011). Recent advances on Ilex paraguariensis research: minireview. Journal of Ethnopharmacology, 136, 378-384.

Bravo, L. (1998). Polyphenols: Chemistry, dietary sources, metabolism, and nutritional significance. Nutrition Reviews, 56, 317-333.

Bravo, L., Goya, L., \& Lecumberri, E. (2007). LC/MS characterization of phenolic constituents of mate (Ilex paraguariensis, St. Hil.) and its antioxidant activity compared to commonly consumed beverages. Food Research International, 40, 393-405.

Bravo, L., Mateos, R., Sarria, B., Baeza, G., Lecumberri, E., Ramos, S., \& Goya, L. (2014) Hypocholesterolaemic and antioxidant effects of yerba mate (Ilex paraguariensis) in highcholesterol fed rats. Fitoterapia, 92, 219-229.

Baeza, G., Sarriá, B., Mateos, R., \& Bravo, L. (2016). Dihydrocaffeic acid, a major microbial metabolite of chlorogenic acids, shows similar protective effect than a yerba mate phenolic extract against oxidative stress in HepG2 cells. Food Research International, 87, 25-33.

Baeza, G., Bachmair, E. M., Wood, S., Mateos, R., Bravo, L., \& de Roos, B. (2017). The colonic metabolites dihydrocaffeic acid and dihydroferulic acid are more effective inhibitors of in 
vitro platelet activation than their phenolic precursors. Food \& Function. DOI: 10.1039/C6FO01404F.

Cardozo, E. L., Ferrarese-Filho, O., Ferrarese, L. L., Donaduzzi, C. M., \& Sturion, J. A. (2007). Methylxanthines and phenolic compounds in mate ("Ilex paraguariensis" St. Hil.) progenies grown in Brazil. Journal of Food Composition and Analysis, 20, 553-558.

Day, A. J., Mellon, F., Barron, D., Sarrazin, G., Morgan, M.R., \& Williamson, G. (2001). Human metabolism of dietary flavonoids: identification of plasma metabolites of quercetin. Free Radical Research, 35, 941-952.

de Mejía, E. G., Song, Y. S., Heck, C. I., \& Ramírez-Mares, M. (2010). Yerba mate tea (Ilex paraguariensis): Phenolics, antioxidant capacity and in vitro inhibition of colon cancer cell proliferation. Journal of Functional Foods, 2, 23-34.

de Morais, E. C., Stefanuto, A., Klein, G. A., Boaventura, B. C., de Andrade, F., Wazlawik, E., Di Pietro, P. F., Maraschin, M., da Silva, E. L. (2009). Consumption of yerba mate (llex paraguariensis) improves serum lipid parameters in healthy dyslipidemic subjects provides an additional LDL-cholesterol reduction in individuals on statin therapy. Journal of Agricultural and Food Chemistry, 57, 8316-8324.

Del Río, D., Rodríguez-Mateos, A., Spencer, J. P., Tognolini, M., Borges, G., \& Crozier, A. (2013). Dietary (poly)phenolics in human health: structures, bioavailability, and evidence of protective effects against chronic diseases. Antioxidants \& Redox Signaling, 18, 1818-1892.

Gao, H., Liu, Z., Qu, X., \& Zhao, Y. (2013). Effects of yerba mate tea (Ilex paraguariensis) on vascular endothelial function and liver lipoprotein receptor gene expression in hyperlipidemic rats. Fitoterapia, 84, 264-272.

Gomez-Juaristi, M. (2015). Metabolism of dietary flavonoids and hydroxycinnamic acids. In vitro transport studies and determination of bioavailability in humans. Universidad Complutense de Madrid (Doctoral Thesis). 
Gómez-Juaristi, M., Martínez, S., Sarriá, B., Bravo, L., \& Mateos, R. (Submitted). Bioavailability of hydroxycinnamate derivatives after consuming an instant green/roasted coffee blend by healthy humans. Food \& Function.

Loomis, D., Guyton, K. Z., Grosse, Y., Lauby-Secretan, B., El Ghissassi, F., Bouvard, V., Benbrahim-Tallaa, L., Guha, N., Mattock, H., \& Straif, K. (2016). Int Agcy Res Canc Monograph. Carcinogenicity of drinking coffee, mate, and very hot beverages. Lancet Oncology, 17, 877-878.

Lubin, J. H., De Stefani E., Abnet, C. C., Acosta, G., Boffetta, P., Victora, C., Graubard, B. I., Muñoz, N., Deneo-Pellegrini, H., Franceschi, S., Castellsagué, X., Ronco, A. L., \& Dawsey, S. M. (2014). Maté drinking and esophageal squamous cell carcinoma in South America: pooled results from two large multicenter case-control studies. Cancer Epidemiology, Biomarkers \& Prevention, 23, 107-116.

Mateos, R., Martínez-López, S., Baeza Arévalo, G., Amigo-Benavent, M., Sarria, B., BravoClemente, L. (2016). Hydroxytyrosol in functional hydroxytyrosol-enriched biscuits is highly bioavailable and decreases oxidised low density lipoprotein levels in humans. Food Chemistry, 205, 248-256.

Pimentel, G. D., Lira, F. S., Rosa, J. C., Caris, A. V., Pinheiro, F., Ribeiro, E. B., Oller do Nascimento, C. M., \& Oyama, L. M. (2013). Yerba mate extract (llex paraguariensis) attenuates both central and peripheral inflammatory effects of diet-induced obesity in rats. The Journal of Nutritional Biochemistry, 24, 809-818.

Redeuil, K., Smarrito-Menozzi, C., Guy, P., Rezzi, S., Dionisi, F., Williamson, G., Nagy, K., \& Renouf, M. (2011). Identification of novel circulating coffee metabolites in human plasma by liquid chromatography-mass spectrometry. Journal of Chromatography A, 1218, 46784688.

Rodríguez-Mateos, A., Vauzour, D., Krueger, C. G., Shanmuganayagam, D., Reed, J., Calani, L., Mena, P., Del Río, D., \& Crozier A. (2014). Bioavailability, bioactivity and impact on health of 
dietary flavonoids and related compounds: an update. Archives of Toxicology, 88, 18031853.

Ronco, A. L., Stefani, E. D., Mendoza, B., Deneo-Pellegrini, H., Vazquez, A., \& Abbona, E. (2016). Mate Intake and Risk of Breast Cancer in Uruguay: a Case- Control Study. Asian Pacific Journal of Cancer Prevention, 17, 1453-61, 2016.

Stalmach, A., Mullen, W., Barron, D., Uchida, K., Yokota, T., Cavin, C., Steiling, H., Williamson, G., \& Crozier, A. (2009). Metabolite Profiling of Hydroxycinnamate Derivatives in Plasma and Urine after the Ingestion of Coffee by Humans: Identification of Biomarkers of Coffee Consumption. Drug Metababolism and Disposition, 37, 1749-1758.

Stalmach, A., Williamson, G., \& Crozier, A. (2014). Impact of dose on the bioavailability of coffee chlorogenic acids in humans. Food \& Function, 5, 1727-1737.

Tomás-Barberán, F., García-Villalba, R., Quartieri, A., Raimondi, S., Amaretti, A., Leonardi, A., \& Rossi, M. (2014). In vitro transformation of chlorogenic acid by human gut microbiota. Molecular Nutrition \& Food Research, 58, 1122-1131. 


\section{Figure Legends}

Figure 1. Plasma concentrations of the identified metabolites after consuming yerba mate. Results represent mean \pm standard deviation $(n=12)$. Gluc: glucuronidate; Sulf: sulfate.

Figure 2. Biotransformation pathways of yerba mate hydroxycinnamates in humans. COMT: catechol-O-methyl transferases; DC: decarboxylases; DH: dehydrogenases; EST: esterases; RED: reductases. 


\section{Figure 1.}
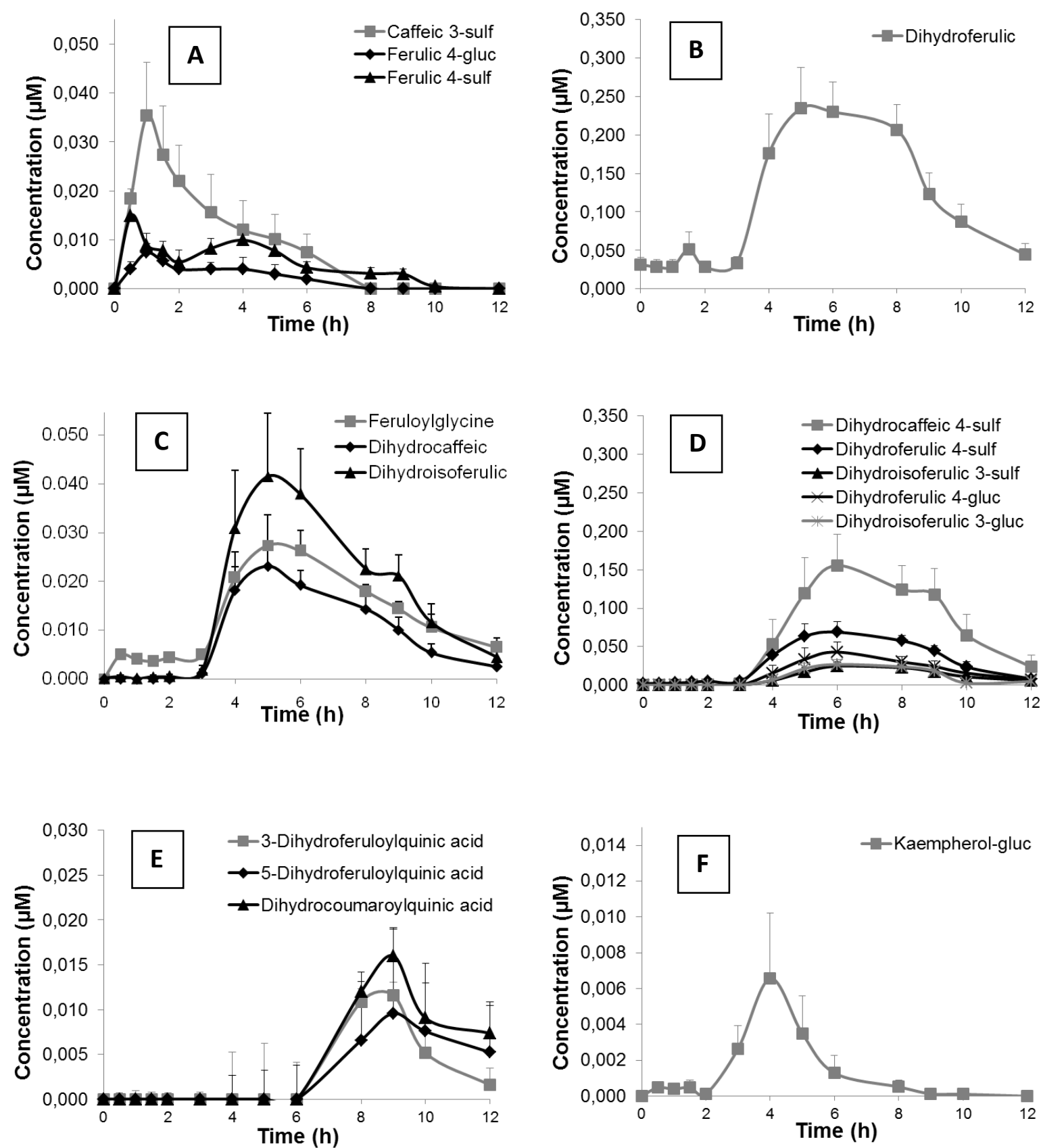
Figure 2.

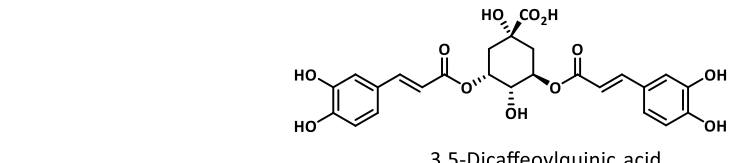

3,5-Dicaffeoylquinic acid

EST

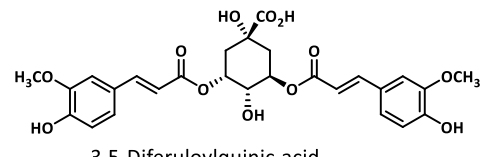

3,5-Diferuloylquinic acid<smiles>O=C(CCc1ccc(O)c(O)c1)O[C@H]1C[C@](O)(C(=O)O)C[C@@H](O)[C@H]1O</smiles>

5-Dihydrocaffeoylquinic acid<smiles>CC(=O)OC1C[C@@](O)(C(=O)O)C[C@@H](O)[C@H]1OC(=O)/C=C/c1ccc(O)c(O)c1</smiles>

5-Caffeoylquinic acid

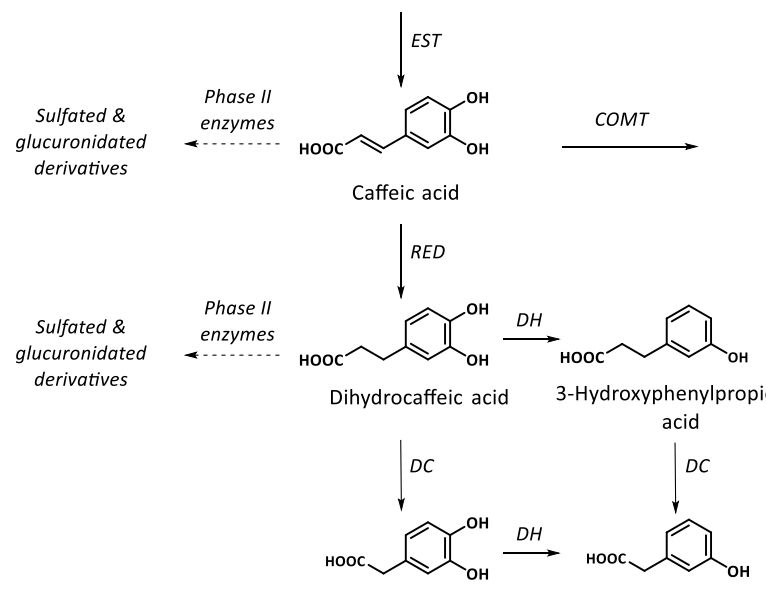

EST<smiles>COc1cc(/C=C/C(=O)OC2C[C@](O)(C(=O)O)C[C@H](O)[C@H]2O)ccc1O</smiles>

5-Feruloylquinic acid

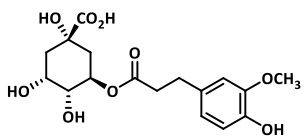

5-Dihydroferuloylquinic acid
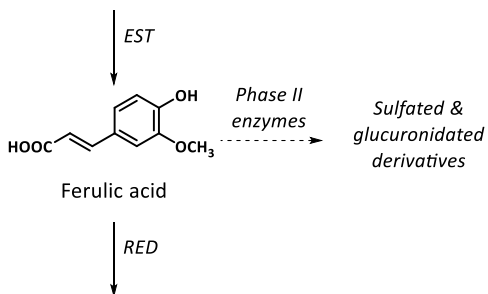

$R E D$

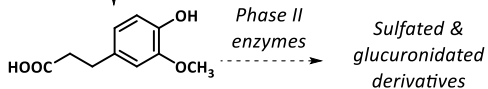

Dihydroferulic acid derivatives

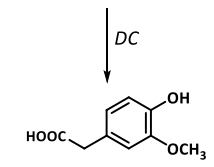

3,4-Dihydroxyphenylacetic acid 3-Hydroxyphenylacetic acid

Homovanillic acid
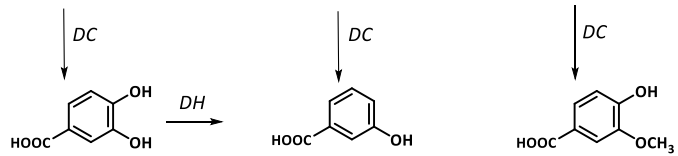

3,4-Dihydroxybenzoic acid

3-Hydroxybenzoic acid 3-Methoxy-4-hydroxybenzoic acid 
Table 1. Phenolic composition of yerba mate infusion determined by HPLC-DAD.

\begin{tabular}{lc}
\hline Phenolic compound & mg/g d.m. (\%) \\
\hline Caffeoylglucose isomers & $3.5 \pm 0.2(4.3 \%)$ \\
Caffeoylquinic acids & $44.5 \pm 0.8(55.2 \%)$ \\
Coumaroylquinic acids & $0.5 \pm 0.1(0.6 \%)$ \\
Feruloylquinic acids & $3.2 \pm 0.1(4.0 \%)$ \\
Caffeoylquinic lactones & $2.7 \pm 0.2(3.4 \%)$ \\
Dicaffeoylquinic acids & $22.4 \pm 0.5(27.8 \%)$ \\
Caffeoylferuloylquinic acids & $0.5 \pm 0.1(0.6 \%)$ \\
Flavonols & $3.3 \pm 0.3(4.1 \%)$ \\
Total Polyphenols & $\mathbf{8 0 . 6} \pm \mathbf{2 . 3 ( 1 0 0 \% )}$ \\
\hline
\end{tabular}

Expressed in mg per gram of dry matter (d.m., $4.85 \%$ moisture). Values in parenthesis represent the percentage of total polyphenols quantified by HPLC. Mean \pm standard deviation $(n=3)$. 
Table 2. LC-QToF identification of hydroxycinnamate esters and flavonol metabolites detected in plasma $(\mathrm{P})$ and urine $(\mathrm{U})$ samples obtained after the ingestion of yerba mate.

\begin{tabular}{|c|c|c|c|c|c|c|}
\hline $\begin{array}{l}\begin{array}{l}\text { Number } \\
\text { peak }\end{array} \\
\end{array}$ & Identified Compound & $\begin{array}{c}\text { RT } \\
\text { (min) }\end{array}$ & $\begin{array}{c}\text { Molecular } \\
\text { formula }\end{array}$ & {$[\mathrm{M}-\mathrm{H}]^{-}$} & $\begin{array}{c}\text { Fragment } \\
\text { MS }^{2}\end{array}$ & Location \\
\hline \multicolumn{7}{|c|}{ Caffeic acid metabolites } \\
\hline 1 & 3-Caffeoylquinic acid & 4.0 & $\mathrm{C}_{16} \mathrm{H}_{18} \mathrm{O}_{9}$ & 353.0878 & 191 & U \\
\hline 2 & 5-Caffeoylquinic acid & 6.2 & $\mathrm{C}_{16} \mathrm{H}_{18} \mathrm{O}_{9}$ & 353.0878 & 191 & $U$ \\
\hline 3 & Caffeic acid 3-sulfate & 10.7 & $\mathrm{C}_{9} \mathrm{H}_{8} \mathrm{O}_{7} \mathrm{~S}$ & 258.9918 & $179 ; 135$ & $P, U$ \\
\hline 4 & Dihydrocaffeic acid & 7.0 & $\mathrm{C}_{9} \mathrm{H}_{10} \mathrm{O}_{4}$ & 181.0506 & 137 & $P, U$ \\
\hline 5 & Dihydrocaffeic acid 3-glucuronide & 6.5 & $\mathrm{C}_{15} \mathrm{H}_{18} \mathrm{O}_{10}$ & 357.0827 & $181 ; 137$ & U \\
\hline 6 & Dihydrocaffeic acid 4-sulfate & 7.8 & $\mathrm{C}_{9} \mathrm{H}_{10} \mathrm{O}_{7} \mathrm{~S}$ & 261.0074 & 181 & $P, U$ \\
\hline 7 & Dihydrocaffeic acid 3-sulfate & 10.4 & $\mathrm{C}_{9} \mathrm{H}_{10} \mathrm{O}_{7} \mathrm{~S}$ & 261.0074 & 181 & $U$ \\
\hline 8 & 3-Dihydrocaffeoylquinic acid & 8.5 & $\mathrm{C}_{16} \mathrm{H}_{20} \mathrm{O}_{9}$ & 355.1035 & 181 & U \\
\hline 9 & Caffeoylquinic lactone sulfate & 12.3 & $\mathrm{C}_{16} \mathrm{H}_{16} \mathrm{O}_{11} \mathrm{~S}$ & 415.0330 & 335 & U \\
\hline \multicolumn{7}{|c|}{ Ferulic acid metabolites } \\
\hline 10 & 3-Feruloylquinic acid & 7.1 & $\mathrm{C}_{17} \mathrm{H}_{20} \mathrm{O}_{9}$ & 367.1035 & 191 & U \\
\hline 11 & 5-Feruloylquinic acid & 9.6 & $\mathrm{C}_{17} \mathrm{H}_{20} \mathrm{O}_{9}$ & 367.1035 & 191 & U \\
\hline 12 & 4-Feruloylquinic acid & 10.2 & $\mathrm{C}_{17} \mathrm{H}_{20} \mathrm{O}_{9}$ & 367.1035 & 191 & $\mathrm{U}$ \\
\hline 13 & isoFerulic acid & 12.9 & $\mathrm{C}_{10} \mathrm{H}_{10} \mathrm{O}_{4}$ & 193.0506 & 134 & $P, U$ \\
\hline 14 & Ferulic acid 4-glucuronide & 8.4 & $\mathrm{C}_{16} \mathrm{H}_{18} \mathrm{O}_{10}$ & 369.0827 & 193 & $P, U$ \\
\hline 15 & isoFerulic acid 3-glucuronide & 9.2 & $\mathrm{C}_{16} \mathrm{H}_{18} \mathrm{O}_{10}$ & 369.0827 & 193 & $\mathrm{U}$ \\
\hline 16 & Ferulic acid 4-sulfate & 8.7 & $\mathrm{C}_{10} \mathrm{H}_{10} \mathrm{O}_{7} \mathrm{~S}$ & 273.0074 & 193 & $P, U$ \\
\hline 17 & Dihydroferulic acid & 10.8 & $\mathrm{C}_{10} \mathrm{H}_{12} \mathrm{O}_{4}$ & 195.0663 & 136 & $P, U$ \\
\hline 18 & Dihydroisoferulic acid & 11.6 & $\mathrm{C}_{10} \mathrm{H}_{12} \mathrm{O}_{4}$ & 195.0663 & 136 & $P, U$ \\
\hline 19 & Dihydroferulic acid 4-glucuronide & 6.5 & $\mathrm{C}_{16} \mathrm{H}_{20} \mathrm{O}_{10}$ & 371.0984 & $195 ; 136$ & $P, U$ \\
\hline 20 & Dihydroisoferulic acid 3-glucuronide & 8.4 & $\mathrm{C}_{16} \mathrm{H}_{20} \mathrm{O}_{10}$ & 371.0984 & $195 ; 136$ & $P, U$ \\
\hline 21 & Dihydroferulic acid 4-sulfate & 8.8 & $\mathrm{C}_{10} \mathrm{H}_{12} \mathrm{O}_{7} \mathrm{~S}$ & 275.0231 & $195 ; 136$ & $P, U$ \\
\hline 22 & Dihydroisoferulic acid 3-sulfate & 10.4 & $\mathrm{C}_{10} \mathrm{H}_{12} \mathrm{O}_{7} \mathrm{~S}$ & 275.0231 & $195 ; 136$ & $P, U$ \\
\hline 23 & 3-Dihydroferuloylquinic acid & 15.1 & $\mathrm{C}_{17} \mathrm{H}_{22} \mathrm{O}_{9}$ & 369.1191 & 195 & $P, U$ \\
\hline 24 & 5-Dihydroferuloylquinic acid & 15.4 & $\mathrm{C}_{17} \mathrm{H}_{22} \mathrm{O}_{9}$ & 369.1191 & 195 & $P, U$ \\
\hline 25 & Feruloylglycine & 8.8 & $\mathrm{C}_{12} \mathrm{H}_{13} \mathrm{O}_{5} \mathrm{~N}$ & 250.0721 & $191 ; 134$ & $P, U$ \\
\hline 26 & isoFeruloylglycine & 9.5 & $\mathrm{C}_{12} \mathrm{H}_{13} \mathrm{O}_{5} \mathrm{~N}$ & 250.0721 & $191 ; 134$ & U \\
\hline \multicolumn{7}{|c|}{ Coumaric acid metabolites } \\
\hline 27 & Coumaroylquinic acid & 16.4 & $\mathrm{C}_{16} \mathrm{H}_{18} \mathrm{O}_{8}$ & 337.0929 & 163 & $P, U$ \\
\hline 28 & Dihydrocoumaric acid & 8.5 & $\mathrm{C}_{9} \mathrm{H}_{10} \mathrm{O}_{3}$ & 165.0557 & 119 & $\mathrm{U}$ \\
\hline 29 & Dihydrocoumaric acid glucuronide & 6.8 & $\mathrm{C}_{15} \mathrm{H}_{18} \mathrm{O}_{9}$ & 341.0878 & 165 & $\mathrm{U}$ \\
\hline 30 & Dihydrocoumaric acid sulfate & 10.6 & $\mathrm{C}_{9} \mathrm{H}_{10} \mathrm{O}_{6} \mathrm{~S}$ & 245.0125 & 165 & $\mathrm{U}$ \\
\hline 31 & Dihydrocoumaroylquinic acid & 14.8 & $\mathrm{C}_{16} \mathrm{H}_{20} \mathrm{O}_{8}$ & 339.1085 & 165 & $P, U$ \\
\hline 32 & Dihydrocoumaroylquinic acid & 15.3 & $\mathrm{C}_{16} \mathrm{H}_{20} \mathrm{O}_{8}$ & 339.1085 & 165 & $P, U$ \\
\hline \multicolumn{7}{|c|}{ Flavonol metabolites } \\
\hline 33 & Methyl-quercetin-glucuronide & 16.6 & $\mathrm{C}_{22} \mathrm{H}_{20} \mathrm{O}_{13}$ & 491.0831 & 315 & $P, U$ \\
\hline 34 & Kaempherol-glucuronide & 12.6 & $\mathrm{C}_{21} \mathrm{H}_{18} \mathrm{O}_{12}$ & 461.0726 & 285 & $P, U$ \\
\hline \multicolumn{7}{|c|}{ Phenolic acids } \\
\hline 35 & 3-Hydroxyphenylpropionic acid & 11.1 & $\mathrm{C}_{9} \mathrm{H}_{10} \mathrm{O}_{3}$ & 165.0557 & 121 & $P, U$ \\
\hline 36 & 3,4-Dihydroxyphenylacetic acid & 5.6 & $\mathrm{C}_{8} \mathrm{H}_{8} \mathrm{O}_{4}$ & 167.0350 & 123 & $P, U$ \\
\hline 37 & 3-Methoxy-4-hydroxyphenylacetic acid & 7.5 & $\mathrm{C}_{9} \mathrm{H}_{10} \mathrm{O}_{4}$ & 181,0506 & 137,122 & $P, U$ \\
\hline 38 & 3-Methoxy-4-hydroxyphenylacetic acid & 8.8 & $\mathrm{C}_{9} \mathrm{H}_{10} \mathrm{O}_{4}$ & 181,0506 & 137,122 & $P, U$ \\
\hline 39 & 3-Hydroxyphenylacetic acid & 7.4 & $\mathrm{C}_{8} \mathrm{H}_{8} \mathrm{O}_{3}$ & 151,0401 & 137,122 & $P, U$ \\
\hline 40 & 3,4-Dihydroxybenzoic & 3.8 & $\mathrm{C}_{7} \mathrm{H}_{6} \mathrm{O}_{4}$ & 153,0193 & 109 & $P, U$ \\
\hline 41 & 3-Methoxy-4-hydroxybenzoic acid & 4.5 & $\mathrm{C}_{8} \mathrm{H}_{8} \mathrm{O}_{4}$ & 167.0350 & 123 & $P, U$ \\
\hline 42 & Hydroxybenzoic acid & 6.1 & $\mathrm{C}_{7} \mathrm{H}_{6} \mathrm{O}_{3}$ & 137.0244 & 93 & $P, U$ \\
\hline 43 & 3-Hydroxyhipuric acid & 11.0 & $\mathrm{C}_{9} \mathrm{H}_{9} \mathrm{O}_{4} \mathrm{~N}$ & 194.0459 & 150 & $P, U$ \\
\hline 44 & 4-Hydroxyhipuric acid & 14.2 & $\mathrm{C}_{9} \mathrm{H}_{9} \mathrm{O}_{4} \mathrm{~N}$ & 194.0459 & 150 & $P, U$ \\
\hline 45 & Floroglucinol & 6.5 & $\mathrm{C}_{6} \mathrm{H}_{6} \mathrm{O}_{3}$ & 125.0244 & 79 & $\mathrm{P}, \mathrm{U}$ \\
\hline
\end{tabular}


Table 3. Nutrikinetic parameters of metabolites detected in human plasma after consumption of yerba mate. Values represent mean \pm standard deviation $(n=12)$.

\begin{tabular}{lllc}
\hline Metabolite & $\mathrm{C}_{\max }(\mu \mathrm{M})$ & $\begin{array}{l}\mathrm{T}_{\max }(\min ) \text { or } \\
\text { Range* }\end{array}$ & $\mathrm{AUC}(\mu \mathrm{M} / \mathrm{min})$ \\
\hline Intestinal Absorption & & & \\
Coumaroylquinic acid & Traces** & $(1.0-1.5)^{*}$ & - \\
Caffeic acid 3-sulfate & $0.037 \pm 0.036$ & $0.8 \pm 0.3$ & $0.106 \pm 0.141$ \\
Ferulic acid 4-glucuronide & $0.011 \pm 0.004$ & $2.1 \pm 1.5$ & $0.044 \pm 0.009$ \\
Ferulic acid 4-sulfate & $0.019 \pm 0.009$ & $0.6 \pm 0.2$ & $0.061 \pm 0.023$ \\
Microbial metabolites & & & \\
Dihydrocaffeic acid & $0.027 \pm 0.014$ & $5.7 \pm 1.6$ & $0.113 \pm 0.058$ \\
Dihydroferulic acid & $0.306 \pm 0.158$ & $6.7 \pm 1.4$ & $1.548 \pm 0.717$ \\
Dihydroisoferulic acid & $0.052 \pm 0.039$ & $6.6 \pm 1.8$ & $0.198 \pm 0.149$ \\
Dihydrocaffeic acid 4-sulfate & $0.188 \pm 0.127$ & $7.1 \pm 1.8$ & $0.834 \pm 0.514$ \\
Dihydroferulic acid 4-glucuronide & $0.056 \pm 0.046$ & $7.5 \pm 1.6$ & $0.216 \pm 0.190$ \\
Dihydroisoferulic acid 3-glucuronide & $0.033 \pm 0.018$ & $7.4 \pm 2.2$ & $0.132 \pm 0.078$ \\
Dihydroferulic acid 4-sulfate & $0.084 \pm 0.047$ & $6.7 \pm 1.6$ & $0.387 \pm 0.196$ \\
Dihydroisoferulic acid 3-sulfate & $0.031 \pm 0.017$ & $7.5 \pm 1.4$ & $0.134 \pm 0.073$ \\
Feruloylglycine & $0.033 \pm 0.017$ & $6.3 \pm 1.9$ & $0.166 \pm 0.061$ \\
3-Dihydroferuloylquinic acid & $0.019 \pm 0.009$ & $9.1 \pm 1.3$ & $0.037 \pm 0.032$ \\
5-Dihydroferuloylquinic acid & $0.047 \pm 0.029$ & $8.9 \pm 1.2$ & $0.117 \pm 0.091$ \\
Dihydrocoumaroylquinic acid & $0.022 \pm 0.009$ & $8.9 \pm 2.2$ & $0.091 \pm 0.068$ \\
Dihydrocoumaroylquinic acid & Traces** & $(8.0-9.0)^{*}$ & - \\
Kaempherol-glucuronide & $0.012 \pm 0.008$ & $4.0 \pm 1.5$ & $0.028 \pm 0.017$ \\
Methyl-quercetin-glucuronide & Traces** & $(4.0-5.0)^{*}$ & - \\
\hline
\end{tabular}

* Indicates the range where the metabolite showed the highest value.

** No pharmacokinetic parameters of this metabolite were determined because its content was at trace levels. 
Table 4. Metabolites excreted in urine (from 0 to $24 \mathrm{~h}$ ) by healthy volunteers after consumption of yerba mate.

\begin{tabular}{|c|c|c|c|c|c|c|c|}
\hline Metabolite & $-2-0 h$ & $0-2 \mathrm{~h}$ & $2-4 \mathrm{~h}$ & $4-8 h$ & $8-12 \mathrm{~h}$ & $12-24 \mathrm{~h}$ & TOTAL ( $\mu \mathrm{mol})$ \\
\hline Intestinal absorption & & & & & & & $0-24 h$ \\
\hline 3-Caffeoylquinic acid & $0.013 \pm 0.013$ & $0.068 \pm 0.016$ & $0.109 \pm 0.032$ & $0.021 \pm 0.019$ & N.D. & N.D. & $0.211 \pm 0.080$ \\
\hline 5-Caffeoylquinic acid & $0.010 \pm 0.010$ & $0.036 \pm 0.006$ & $0.054 \pm 0.008$ & $0.011 \pm 0.005$ & N.D. & N.D. & $0.111 \pm 0.029$ \\
\hline 3-Feruloylquinic acid & $0.049 \pm 0.028$ & $0.106 \pm 0.016$ & $0.177 \pm 0.022$ & $0.036 \pm 0.015$ & $0.006 \pm 0.006$ & $0.009 \pm 0.009$ & $0.383 \pm 0.087$ \\
\hline 5-Feruloylquinic acid & $0.020 \pm 0.020$ & $0.159 \pm 0.025$ & $0.308 \pm 0.058$ & $0.138 \pm 0.009$ & $0.042 \pm 0.022$ & N.D. & $0.667 \pm 0.134$ \\
\hline 4-Feruloylquinic acid & $0.024 \pm 0.024$ & $0.186 \pm 0.026$ & $0.283 \pm 0.052$ & $0.013 \pm 0.009$ & N.D. & N.D. & $0.506 \pm 0.111$ \\
\hline Coumaroylquinic acid & $0.021 \pm 0.015$ & $0.010 \pm 0.007$ & $0.017 \pm 0.009$ & $0.087 \pm 0.029$ & $0.245 \pm 0.038$ & $0.149 \pm 0.032$ & $0.529 \pm 0.098$ \\
\hline isoFerulic acid & N.D. & $0.120 \pm 0.079$ & $0.063 \pm 0.063$ & $0.075 \pm 0.075$ & $0.870 \pm 0.087$ & $0.153 \pm 0.108$ & $1.281 \pm 0.304$ \\
\hline Caffeic acid 3-sulfate & $0.263 \pm 0.263$ & $1.273 \pm 0.256$ & $1.839 \pm 0.423$ & $0.855 \pm 0.184$ & $0.587 \pm 0.120$ & $0.032 \pm 0.022$ & $4.849 \pm 1.268$ \\
\hline Ferulic acid 4-glucuronide & N.D. & $0.224 \pm 0.032$ & $0.700 \pm 0.137$ & $0.987 \pm 0.301$ & $0.892 \pm 0.281$ & $0.164 \pm 0.032$ & $2.967 \pm 0.751$ \\
\hline isoFerulic acid 3-glucuronide & $0.159 \pm 0.159$ & $0.051 \pm 0.051$ & $0.101 \pm 0.051$ & $0.022 \pm 0.022$ & $0.016 \pm 0.016$ & N.D. & $0.349 \pm 0.299$ \\
\hline Ferulic acid 4-sulfate & N.D. & $0.485 \pm 0.155$ & $1.744 \pm 0.536$ & $2.651 \pm 0.678$ & $3.076 \pm 1.191$ & $0.196 \pm 0.132$ & $8.152 \pm 2.560$ \\
\hline Caffeoylquinic lactone sulfate & N.D. & $0.075 \pm 0.046$ & $0.041 \pm 0.009$ & N.D. & N.D. & N.D. & $0.116 \pm 0.055$ \\
\hline TOTAL & $0.559 \pm 0.532$ & $2.793 \pm 0.715$ & $5.436 \pm 1.400$ & $4.896 \pm 1.346$ & $5.734 \pm 1.761$ & $0.703 \pm 0.335$ & $20.121 \pm 5.754$ \\
\hline \multicolumn{8}{|l|}{ Colonic absorption } \\
\hline Dihydrocaffeic acid & $0.045 \pm 0.014$ & $0.054 \pm 0.014$ & $0.295 \pm 0.072$ & $0.941 \pm 0.147$ & $1.013 \pm 0.383$ & $0.077 \pm 0.036$ & $2.425 \pm 0.666$ \\
\hline Dihydroferulic acid & $0.056 \pm 0.014$ & $0.083 \pm 0.034$ & $1.041 \pm 0.275$ & $3.264 \pm 0.712$ & $2.129 \pm 0.379$ & $0.145 \pm 0.054$ & $6.718 \pm 1.468$ \\
\hline Dihydrocoumaric acid & $0.034 \pm 0.013$ & $0.041 \pm 0.016$ & $0.144 \pm 0.025$ & $0.316 \pm 0.050$ & $0.397 \pm 0.070$ & $0.122 \pm 0.022$ & $1.054 \pm 0.196$ \\
\hline Dihydrocaffeic acid 3-glucuronide & N.D. & $0.008 \pm 0.005$ & $0.052 \pm 0.018$ & $0.226 \pm 0.032$ & $0.226 \pm 0.059$ & $0.018 \pm 0.013$ & $0.530 \pm 0.127$ \\
\hline Dihydrocaffeic acid 4-sulfate & $0.161 \pm 0.056$ & $0.216 \pm 0.051$ & $0.360 \pm 0.132$ & N.D. & $0.126 \pm 0.088$ & $0.519 \pm 0.163$ & $1.382 \pm 0.49$ \\
\hline Dihydrocaffeic 3-sulfate & N.D. & N.D. & $3.739 \pm 1.959$ & $15.432 \pm 4.018$ & $15.723 \pm 3.268$ & $3.887 \pm 2.824$ & $38.781 \pm 12.069$ \\
\hline Dihydroferulic acid 4-glucuronide & N.D. & $0.047 \pm 0.023$ & $0.600 \pm 0.152$ & $2.708 \pm 0.826$ & $2.614 \pm 0.588$ & $0.393 \pm 0.093$ & $6.362 \pm 1.682$ \\
\hline Dihydroisoferulic acid 3-glucuronide & $0.137 \pm 0.055$ & $0.145 \pm 0.079$ & $0.314 \pm 0.100$ & $2.135 \pm 0.696$ & $1.486 \pm 0.242$ & $0.324 \pm 0.054$ & $4.541 \pm 1.226$ \\
\hline Dihydroferulic acid 4-sulfate & $0.824 \pm 0.413$ & $1.350 \pm 1.025$ & $2.697 \pm 1.081$ & $5.986 \pm 1.818$ & $7.074 \pm 1.508$ & $1.950 \pm 0.479$ & $19.882 \pm 6.324$ \\
\hline Dihydroisoferulic acid 3-sulfate & N.D. & N.D. & $0.316 \pm 0.210$ & $1.577 \pm 0.516$ & $1.718 \pm 0.324$ & $0.159 \pm 0.073$ & $3.770 \pm 1.123$ \\
\hline Dihydrocumaric glucuronide & $0.016 \pm 0.009$ & $0.004 \pm 0.004$ & $0.059 \pm 0.018$ & $0.126 \pm 0.024$ & $0.236 \pm 0.029$ & $0.075 \pm 0.019$ & $0.516 \pm 0.103$ \\
\hline Dihydrocoumaric sulfate & $0.102 \pm 0.055$ & $0.135 \pm 0.039$ & $0.249 \pm 0.065$ & $0.932 \pm 0.352$ & $2.683 \pm 0.452$ & $4.345 \pm 1.217$ & $8.446 \pm 2.180$ \\
\hline
\end{tabular}




\begin{tabular}{|c|c|c|c|c|c|c|c|}
\hline Metabolite & $-2-0 h$ & $0-2 \mathrm{~h}$ & $2-4 \mathrm{~h}$ & $4-8 \mathrm{~h}$ & $8-12 \mathrm{~h}$ & $12-24 \mathrm{~h}$ & TOTAL ( $\mu \mathrm{mol})$ \\
\hline Colonic absorption (continued) & & & & & & & $(0-24 \mathrm{~h})$ \\
\hline 3-Dihydrocaffeoylquinic acid & $0.027 \pm 0.011$ & $0.018 \pm 0.008$ & $0.024 \pm 0.015$ & $0.086 \pm 0.029$ & $0.192 \pm 0.088$ & $0.145 \pm 0.061$ & $0.492 \pm 0.212$ \\
\hline 3-Dihydroferuloylquinic acid & $0.011 \pm 0.008$ & $0.008 \pm 0.006$ & $0.091 \pm 0.028$ & $0.111 \pm 0.031$ & $0.947 \pm 0.419$ & $0.170 \pm 0.044$ & $1.338 \pm 0.536$ \\
\hline 5-Dihydroferuloylquinic acid & $0.026 \pm 0.014$ & $0.007 \pm 0.006$ & $0.102 \pm 0.084$ & $0.109 \pm 0.035$ & $2.864 \pm 0.389$ & $0.651 \pm 0.182$ & $3.759 \pm 0.710$ \\
\hline Dihydrocoumaroylquinic acid & $0.055 \pm 0.027$ & $0.070 \pm 0.010$ & $0.182 \pm 0.041$ & $0.381 \pm 0.137$ & $0.848 \pm 0.131$ & $0.197 \pm 0.032$ & $1.733 \pm 0.378$ \\
\hline Dihydrocoumaroylquinic acid & $0.008 \pm 0.025$ & $0.008 \pm 0.006$ & $0.030 \pm 0.010$ & $0.053 \pm 0.009$ & $0.597 \pm 0.121$ & $0.346 \pm 0.035$ & $1.042 \pm 0.206$ \\
\hline Feruloylglycine & $0.381 \pm 0.093$ & $0.321 \pm 0.060$ & $2.461 \pm 0.902$ & $10.606 \pm 2.560$ & $10.740 \pm 4.149$ & $1.258 \pm 0.467$ & $25.767 \pm 8.231$ \\
\hline isoFeruloylglycine & N.D. & N.D. & $0.070 \pm 0.027$ & $0.331 \pm 0.066$ & $0.222 \pm 0.076$ & $0.014 \pm 0.014$ & $0.637 \pm 0.183$ \\
\hline Kaempherol-glucuronide & N.D. & N.D. & $0.072 \pm 0.007$ & $0.196 \pm 0.022$ & N.D. & N.D. & $0.268 \pm 0.029$ \\
\hline Methyl-quercetin-glucuronide & N.D. & N.D. & N.D. & N.D. & $<$ L.Q. & $<$ L.Q. & Traces \\
\hline TOTAL microbial metabolites & $1.883 \pm 0.807$ & $2.515 \pm 1.386$ & $12.898 \pm 5.221$ & $45.516 \pm 12.080$ & $51.835 \pm 12.763$ & $14.795 \pm 5.883$ & $129.442 \pm 38.139$ \\
\hline \multicolumn{8}{|l|}{ Other microbial metabolites } \\
\hline 3-Hydroxyphenylpropionic acid & $0.019 \pm 0.007$ & $0.003 \pm 0.002$ & $0.047 \pm 0.007$ & $0.262 \pm 0.109$ & $0.552 \pm 0.136$ & $0.100 \pm 0.018$ & $0.983 \pm 0.279$ \\
\hline 3.4-Dihydroxyphenylacetic acid & $0.097 \pm 0.017$ & $0.071 \pm 0.028$ & $0.062 \pm 0.019$ & $0.060 \pm 0.015$ & $0.029 \pm 0.018$ & $0.057 \pm 0.021$ & $0.376 \pm 0.118$ \\
\hline 3-Methoxy-4-hydroxyphenylacetic acid & N.D. & $<$ L.Q. & $0.444 \pm 0.184$ & $1.471 \pm 0.324$ & $0.404 \pm 0.128$ & $0.062 \pm 0.040$ & $2.381 \pm 0.676$ \\
\hline 4-Methoxy-3-hydroxyphenylacetic acid & $0.172 \pm 0.040$ & $0.134 \pm 0.044$ & $0.152 \pm 0.039$ & $0.241 \pm 0.031$ & $0.552 \pm 0.063$ & $0.237 \pm 0.031$ & $1.488 \pm 0.248$ \\
\hline 3-Hydroxyphenylacetic acid & $0.256 \pm 0.046$ & $0.164 \pm 0.214$ & $0.317 \pm 0.060$ & $0.359 \pm 0.067$ & $0.761 \pm 0.148$ & $0.387 \pm 0.070$ & $2.244 \pm 0.605$ \\
\hline Protocatechuic acid & $0.065 \pm 0.023$ & $0.034 \pm 0.008$ & $0.035 \pm 0.009$ & $0.041 \pm 0.006$ & $0.059 \pm 0.009$ & $0.057 \pm 0.008$ & $0.291 \pm 0.063$ \\
\hline Vanillic acid & $0.153 \pm 0.044$ & $0.072 \pm 0.015$ & $0.130 \pm 0.028$ & $0.139 \pm 0.025$ & $0.288 \pm 0.036$ & $0.282 \pm 0.055$ & $1.064 \pm 0.203$ \\
\hline Hydroxybenzoic acid & $0.046 \pm 0.012$ & $0.091 \pm 0.027$ & $0.168 \pm 0.101$ & $0.085 \pm 0.011$ & $0.143 \pm 0.019$ & $0.162 \pm 0.039$ & $0.695 \pm 0.208$ \\
\hline 4-hydroxyhipuric acid & N.D. & N.D. & N.D. & N.D. & $0.086 \pm 0.011$ & N.D. & $0.086 \pm 0.011$ \\
\hline 3-hydroxyhipuric acid & N.D. & N.D. & N.D. & N.D. & $0.084 \pm 0.013$ & N.D. & $0.084 \pm 0.013$ \\
\hline Floroglucinol & $0.285 \pm 0.063$ & $0.122 \pm 0.030$ & $0.155 \pm 0.029$ & $0.184 \pm 0.031$ & $0.311 \pm 0.046$ & $0.458 \pm 0.124$ & $1.515 \pm 0.323$ \\
\hline Total other microbial metabolites & $1.093 \pm 0.245$ & $0.691 \pm 0.368$ & $1.510 \pm 0.476$ & $2.842 \pm 0.619$ & $3.269 \pm 0.626$ & $1.802 \pm 0.406$ & $11.207 \pm 2.747$ \\
\hline
\end{tabular}

8 L.Q.: limit of quantification; N.D.: Not detected. 